\title{
O ALINHAMENTO DO PENSAMENTO FREIREANO COM O SER HUMANO: análise de frequência de palavras do livro Pedagogia da Autonomia
}

\author{
José Pedro Guimarães da Silva' \\ Maria Julieta Fai Serpa e Sales² \\ Maria Marina Dias Cavalcante 3
}

\section{RESUMO}

Na envergadura do cenário atual, uma parcela da sociedade atribuiu a Paulo Freire o juízo de doutrinador, questionando suas ideias e supondo que suas obras possuem o intuito de reproduzir um comunismo apontado como chaga, motivo pelo qual este artigo posiciona-se politicamente em defesa deste educador. Mesmo porque, consoante a lógica freireana, o posicionamento é uma atitude política. Nesse intuito, apresentam-se dados que ratificam a preocupação de Paulo Freire com uma Pedagogia pautada em ideais de valorização do ser humano. $O$ objetivo geral direciona-nos a discutir conceitos da Pedagogia Freireana a partir das sete palavras mais frequentes no livro Pedagogia da Autonomia. Com relação à metodologia, esta pesquisa enquadra-se no enfoque qualitativo com a utilização da modalidade de análise lexical, circunscrita ao método de análise de conteúdo. Os dados foram obtidos através da utilização do programa de análise qualitativa Nvivo $^{\circledR}$, por meio da investigação de frequência de palavras. Por fim, o exame dos dados permitiu-nos debater a dialogicidade entre os sujeitos, conhecimentos e práticas necessários à práxis pedagógica, bem como outros princípios pedagógicos discutidos por Freire.

Palavras-chave: Paulo Freire. Pedagogia da Autonomia. Análise Lexical.

\section{ALIGNING FREIREAN THOUGHT WITH HUMAN BEING: analysis of word frequency}

\section{in the book Pedagogy of Autonomy}

\footnotetext{
1 Doutorando do Programa de Pós-Graduação em Educação da Universidade Estadual do Ceará. Professor Assistente da Universidade Estadual do Ceará, lotado no CECITEC, Tauá, Ceará, Brasil. Bolsista da Fundação Cearense de Apoio ao Desenvolvimento Científico e Tecnológico (FUNCAP). Orcid iD: https://orcid.org/0000-0001-5070-9753. E-mail: pedro.guimaraes@uece.br

2 Mestranda do Programa de Pós-Graduação em Educação da Universidade Estadual do Ceará, Fortaleza, Ceará, Brasil. Bolsista CAPES em regime de Dedicação Exclusiva. Orcid iD: https://orcid.org/0000-0002-1786-1339. E-mail: julieta.sales@aluno.vece.br

3 Doutora em Educação Brasileira pela Universidade Federal do Ceará. Professora do Programa de Pós-Graduação em Educação da Universidade Estadual do Ceará, Fortaleza, Ceará, Brasil. Orcid iD: https://orcid.org/0000-0003-4443-4778. E-mail: maria.marina@uece.br
} 


\section{ABSTRACT}

Under the current scenario, a portion of society attributed to Paulo Freire the judgment of indoctrinator, questioning his ideas and assuming that his works are intended to reproduce a communism pointed out as chaga, the reason this article is politically positioned in defense of that educator. Not least since, according to the freirean logic, positioning is a political attitude. In this sense, data are presented to confirm Paulo Freire's concern with a Pedagogy based on ideals of valuing the human being. The research aim directs us to discuss concepts of Freirean Pedagogy from the seven most frequent words in the book Pedagogy of Autonomy. Regarding the methodology, this study fits into the qualitative approach with the use of the lexical analysis modality, circumscribed in the content analysis method. The data were collected through the use of the qualitative analysis program Nvivo $\AA_{\text {, through }}$ word frequency investigation. Finally, the examination of the data allowed us to discuss the dialogue between the subjects, knowledge and practices necessary to pedagogical praxis, as well as other pedagogical principles discussed by Freire.

Keywords: Paulo Freire. Pedagogy of Autonomy. Lexical analysis.

\section{LA ALINEACIÓN DEL PENSAMIENTO FREIREANO CON EL SER HUMANO: análisis de frecuencia de palabras del libro Pedagogía de la Autonomía}

\section{RESUMEN}

Existe un cierto debate que atribuyó a Paulo Freire el juicio de adoctrinador, cuestionando sus ideas y suponiendo que sus obras tienen como objetivo generar uma forma de comunismo en su discurso. Este artículo tiene como objetivo comprender el pensamento de este autor y generar una posición para el análisis de lo político y su relación con el campo educativo. El trabajo presenta datos que ratifican la preocupación de Paulo Freire por una Pedagogía basada en los ideales de valoración del ser humano y se discute respecto de las siete palabras más frecuentes del libro Pedagogía de la autonomía. La metodologia de este trabajo es cualitativa utilizando la modalidad de análisis léxico y de contenido. Los datos se obtuvieron por medio del uso del programa de análisis cualitativo Nvivo®, mediante la investigación de la frecuencia de palabras. Finalmente, el examen de los datos permite debatir el diálogo entre los sujetos, conocimientos y prácticas necesarios para la praxis pedagógica, así como otros principios pedagógicos discutidos por Freire.

Palabras clave: Paulo Freire. Pedagogía de la Autonomía. Análisis léxico.

\section{INTRODUÇÃO}

Vivenciamos no Brasil, ao longo dos últimos tempos, um momento singular em que assistimos à transição de sucessivos governos presidenciais de esquerda para gestões que aproximam-se da tendência ultra-direitista neoliberal. Os dois últimos governos em exercício - de Agosto de 2016 a 
Janeiro de 2018 e de Janeiro de 2019 até o presente momento inauguraram os primeiros mandatos presidenciais de linha conservadora após um período de 13 anos. Nesta conjuntura de mudanças observamos o germinar de uma cultura do ódio que introduziu em nosso meio uma polarização cujos reflexos alcançaram muitos setores - economia, cultura, saúde, inclusive a educação - com discursos e ações que fizeram brotar a semente da discórdia na sociedade civil.

Cumpre registrar a ocorrência de episódios que excedem ao enfrentamento no campo do discurso e materializam-se em atos de violência física, psicológica e até mortes. Desse modo, o constatar dos fatos representa um ato revolucionário porque tem em vista a ação contraditória de reagir e não se render, em que pese a atual situação vivenciada.

Como uma das consequências deste quadro, destacamos o proferimento de ataques a Paulo Freire, patrono da educação brasileira, um dos educadores mais respeitados no mundo. A fim de compreendermos $O$ reconhecimento e a repercussão do legado freireano, encontramos em Polli (2008, p. 10-11) uma síntese que exprime a importância intelectual do educador:

Paulo Freire é um dos brasileiros mais conhecidos no exterior. $\bigcirc$ reconhecimento de sua obra é notório no Brasil e em vários países em que sua teoria tocou o solo fértil. Nas instituições de ensino espalhadas pelo Brasil, dezenas levam seu nome, bem como diretórios acadêmicos e centros de estudo e pesquisa. Esse reconhecimento vem também pelos inúmeros prêmios internacionais, criação de cátedras em universidades, programas de pesquisa sobre sua teoria e pelas quatro dezenas de títulos de Doutor Honoris Causa em diversas universidades espalhadas pelo globo. Freire também obteve três títulos de professor emérito, dois em universidade brasileiras e um nos E.U.A. Há um monumento na cidade de Estocolmo, com a reprodução das imagens de 7 grandes personalidades mundiais que lutaram contra a opressão: Pablo Neruda, Ângela Davis, Máo Tse-Tung, Sara Lidman, Elise Ottosson-Jense, Georg Borgström e Paulo Freire. Por ter visitado mais de 50 países, Freire levou sua obra e deixou seu legado pelos quatro cantos do planeta, circulando em contato com os grandes nomes do pensamento contemporâneo. Escreveu mais de duas dezenas de importantes obras. Talvez a mais conhecida e impactante tenha sido a Pedagogia do Oprimido. Todas essas obras foram publicadas em pelo menos cinco línguas. A 
Pedagogia do Oprimido, pela extensão de sua influência no pensamento pedagógico mundial, foi publicada também em japonês, hindu, ídiche, sueco, holandês, basco e dinamarquês.

Considerando a importância e reconhecimento mundial de Paulo Freire aliada à conjuntura atual que elegeu o educador para sofrer uma espécie de linchamento intelectual, fundamentado em opiniões e informações sem o devido rigor científico, expressamos para além dos objetivos metodológicos concernentes à toda pesquisa científica, nosso objetivo político neste artigo: demonstrar por meio de dados científicos fundamentados na obra de Paulo Freire a preocupação do autor em apresentar uma Pedagogia pautada em ideais de valorização do ser humano.

Destarte, é importante reconhecer a necessidade de refletirmos acerca das circunstâncias por que passa o professor neste período, em que pese o histórico de políticas que obstaculizam a valorização do magistério e reduzem a prática de ensino a um acúmulo de informações, distanciando-a do conhecimento. Além disso, há indícios de que o neoliberalismo no ensino prejudica $\circ$ aprendizado e o senso crítico. Compreendemos que esta iniciativa contribui para reiterar a conjuntura de desigualdades de acesso à educação e ao aumento das disparidades.

Ademais, em relação a outros aspectos do texto, cumpre realçar que este artigo emergiu do componente curricular intitulado "Seminário de Prática de Pesquisa IV", do Doutorado Acadêmico em Educação de uma universidade pública. Neste componente destacamos como um dos objetivos a apresentação de algumas alternativas e ferramentas de análise qualitativa, entre as quais a utilização do programa Nvivo®, versão 11 (QSR International, 2015).

Metodologicamente, este estudo enquadra-se na abordagem qualitativa de pesquisa (FLICK, 2009) e ao método de Análise de Conteúdo, mais especificamente pela utilização de elementos da modalidade de análise lexical (BARDIN, 2009; MINAYO, 2013). Para o tratamento do conteúdo escolhido, utilizamos o livro Pedagogia da Autonomia, de Paulo 
Freire. Em obediência ao recorte metodológico, a opção de análise escolhida no programa consistiu em realizar a determinação da frequência de palavras, o que permitiu compreender o número de ocorrências das palavras na obra em tela.

Em relação aos objetivos, este artigo apresentou como objetivo geral discutir conceitos da Pedagogia Freireana a partir dos sete vocábulos mais frequentes no livro Pedagogia da Autonomia e como objetivos específicos, identificar as sete palavras mais frequentes referente a obra e relacionar as mesmas palavras a unidades temáticas, para melhor análise dos vocábulos.

Por fim, eximir-nos-emos de apresentar uma biografia de Paulo Freire, já que encontram-se várias biografias resumidas em diversos blogues e sítios da Internet. Por certo, o leitor poderá também encontrar edições de biografias escritas e organizadas por pessoas que conviveram com Paulo Freire, que naturalmente brindam o leitor com muitos detalhes da vida desse grande educador.

Do mesmo modo, não vamos apresentar uma resenha da obra Pedagogia da Autonomia, por estarem disponíveis versões de vários autores em blogues e periódicos científicos da área de Educação. Optamos por escrever nas próximas subseções sobre o contexto de produção da obra Pedagogia da Autonomia e alguns princípios gerais da Pedagogia Freireana.

\section{CONTEXTO DE PRODUÇÃO DA OBRA PEDAGOGIA DA AUTONOMIA}

O livro Pedagogia da Autonomia, publicado em 1996, foi o último livro escrito por Paulo Freire em vida, que faleceu no ano seguinte. Pode ser um livro pequeno, se considerarmos a quantidade de capítulos (3) e páginas (146), consideramos que é de fácil entendimento, porém não deve ser lido de forma descuidada. Como o autor enfatiza na própria obra, "[...] qualquer texto necessita que o leitor ou a leitora a ele se entregue de forma crítica, crescentemente curiosa" (FREIRE, 1996, p. 20). Com o coração aberto ao novo que lhe é apresentado.

O fato de escolhermos a última obra escrita por Paulo Freire conferenos a vantagem de encontrarmos nela temas discutidos em obras anteriores, 
como o próprio autor indica: "[...] alguns dos aspectos aqui discutidos não tem sido estranhos a análises feitas em livros meus anteriores, [...] sobretudo quando a retomada do tema não é pura repetição do que foi dito" (FREIRE, 1996, p. 13).

Sendo assim, considerando as observações destacadas, encontramos em Lima (2011, p. 3-4) o depoimento que corrobora a pertinência dos destaques de Paulo Freire:

Com efeito, em Pedagogia da Autonomia Freire procede a uma "retomada de problemas" que o haviam ocupado ao longo das três décadas anteriores, razão pela qual creio que uma leitura insular desta obra, embora sendo possível e, até, não lhe retirando impacto, será, porém incapaz de aceder aos níveis mais profundos e elaborados da sua construção. $O$ livrinho aparentemente simples e acessível que, na verdade, nunca deixa de ser, transfigura-se aos olhos de quem conhece Freire na sua plenitude intelectual e na sua sofisticação argumentativa, parecendo encerrar uma dupla condição: a de introdução à reflexão crítica sobre o acto de ensinar, numa "linguagem acessível e didática" (nas palavras do seu discípulo Moacir Gadotti), mas também a de síntese, revisitação e recontextualização de alguns dos tópicos centrais à obra escrita que edificou desde a década de 1960.

Outrossim, com base em uma leitura crítica e rigorosa, traçaremos sinteticamente na próxima subseção um quadro com alguns princípios gerais da Pedagogia Freireana, baseando-nos principalmente na obra Pedagogia da Autonomia, sem contudo atermo-nos exclusivamente a ela.

\section{A essencialidade do diálogo como elemento constituinte da práxis educativa no olhar de Paulo Freire}

O ato de comunicar que está imbricado na linha de pensamento freireano vislumbra situações de intercâmbio de concepções pautadas pela liberdade que guia as relações para a formação de recíprocos aprendizados. Criando assim, oportunidades para o desenvolvimento do senso crítico.

No que diz respeito aos contextos educacionais em que ocorrem a prática pedagógica propriamente dita, Freire (1996) pontua a necessidade 
de haver espaço para o reconhecimento das especificidades do outro, criando um ambiente propício à formação integral dos educandos, bem como para as trocas que são viabilizadas pelo diálogo. Uma importante discussão, uma vez que, de acordo com o pensamento de Betto (2018, p. 59), "a escola, na sua tradição ocidental e brasileira, por razões históricas e cartesianas, esquece a questão da subjetividade, uma das duas dimensões essenciais do ser humano". Isto posto, devemos enfatizar a narrativa de Pedagogia da Autonomia, que traz em suas linhas o despertar para a inclusão do campo dos afetos na dimensão da Didática, contribuindo para a criação de sementes com raízes no coletivo.

Portanto, esta obra de Paulo Freire traz um importante contributo para a educação porque coloca em evidência os professores e as professoras, dando ênfase às condições de trabalho desses profissionais. Os passos dados para sua análise revelam 0 propósito educativo de idealizar uma concepção de Didática que tenha como eixo a dialética missão de ressignificar a realidade, construindo alternativas humanas e emancipatórias, fazendo prevalecer o diálogo entre os atores envolvidos no processo de ensino-aprendizagem (MELO, 2018). Consoante Franco (2017, p. 153), a criticidade é um ingrediente visceral que permite a formação dos sujeitos em sua integralidade, e "[...] a ausência desta perspectiva crítica impede a presença de processos dialogais e emancipatórios". Confirmando, portanto, a essencialidade do pensamento freireano que se enraíza na defesa de uma pedagogia crítica.

Nessa linha de pensamento, Freire (1996, p. 38) afirma que "[...] a prática docente crítica, implicante do pensar certo, envolve o movimento dinâmico, dialético, entre o fazer e o pensar sobre o fazer". Um movimento que convoca os educadores a viverem em estado de pesquisa acerca de sua práxis, criando espaços para a reflexão.

Nas palavras de Franco (2017), "[...] a construção do conhecimento se fará na prática dialógica [...], jamais como transmissão de informações sem vinculação à realidade dos educandos ou dos educadores [...]", ou seja, aproximando de fato o conhecimento dos sujeitos, democratizando o 
ensino. Em consequência, ratifica a busca por mudanças na seara educacional que tenham como norte o espírito de solidariedade.

O diálogo, nesse ínterim, aparece como elemento-chave para a concretização dessa proposta defendida por Freire (1996), e propõe uma permanente problematização que vai na contramão da perspectiva neoliberal para o enxergar das contradições, compreendendo a Educação como construção a ser viabilizada pelo coletivo em harmonia, assumindo uma identidade humanizada e humanizadora (FRANCO, 2017).

Aqui, o campo subjetividades ganha força, de mãos dadas com a perspectiva do afeto para então engendrar significativas propostas que coloquem em relevo os sentimentos, entendendo a necessidade de acolher especificidades tanto das pessoas com quem se convive, como do próprio meio (MELO, 2018).

Destarte, a preocupação com as páginas de nossa história que criaram uma cultura de limitações à construção do conhecimento é abordada por Betto (2018, p. 84) quando anuncia: "privatiza-se o existir, encerra-se no individualismo que se gaba de sua indiferença frente aos dramas alheios, e predomina a insensibilidade às questões coletivas [...]". Ou seja, inquieta-se sobremaneira com a concepção educativa que se inclina para a indiferença e falta de empatia. Nesse sentido, reafirma a importância do legado da obra Pedagogia da Autonomia, que traz justamente uma alternativa visando a mudanças desse paradigma em que o diálogo é posto como alicerce das relações sociais, enfatizando o vínculo e a capacidade de acolher o outro.

Por fim, Franco (2012, p. 68) destaca: "[...] Paulo Freire vê na educação uma forma política de transformar a sociedade, para que esta se torne mais justa e mais solidária", o que seria para ele viabilizado pelo diálogo. Assim os sujeitos podem de forma consciente ultrapassar as barreiras que impedem de humanizar a educação, para então emancipar a todos (FREIRE, 1996).

Sendo assim, o processo educativo como meio de promover a emancipação humana, apenas se concretiza como atividade coletiva de educadores e educandos, imbuídos em alcançar a transformação social. Em 
outros termos, esta atividade coletiva orientada para este fim, constitui-se práxis educativa, que será abordada a seguir.

Dentro desta perspectiva, depois da construção do conhecimento mediada pela postura dialógica do educador e dos educandos, cuja reflexão sobre o mundo social é um requisito central, faz-se necessário a modificação da realidade, pois a Pedagogia Freireana é baseada nas etapas de ação-reflexão-ação. Tal processo parte da problematização da prática e saberes cotidianos dos educandos, passa pela reflexão sobre a realidade, a partir dos saberes sociais sistematizados e tem como culminância a modificação da realidade dos educandos, cônscios de sua condição no mundo social.

Nessa linha, o primeiro passo para entendermos o que vem a ser práxis educativa ou pedagógica na concepção freireana é compreendermos o processo dialético entre ação-reflexão ou teoria-prática. Desta forma, como ponto de partida, vamos encontrar em Vázquez (2011, p. 239) o seguinte esclarecimento:

[...] a práxis se apresenta como atividade material, transformadora e adequada a fins. Fora dela fica a atividade teórica que não se materializa, na medida que é atividade espiritual pura. Mas, entretanto, não há práxis como atividade puramente material, isto é, sem a produção de fins e conhecimentos que caracteriza a atividade teórica. Isso significa que o problema de determinar o que é práxis requer delimitar mais profundamente as relações entre teoria e prática.

Em consequência, para o autor, a práxis é reafirmada como atividade com fins estabelecidos e que visa à transformação, além de ter sua base estabelecida na relação filosófica entre teoria e prática. Entretanto, retomando o último período do excerto anterior, no sentido de delimitar mais profundamente as relações entre teoria e prática, vamos ainda em Vázquez (2011, p. 266) encontrar o seguinte ensinamento:

Esta, como atividade ao mesmo tempo subjetiva e objetiva, como unidade do teórico com o prático, na própria ação, é transformação objetiva, real, na matéria através da qual se 
objetiva ou realiza um fim; é, portanto, realização guiada por uma consciência que, ao mesmo tempo, só guia ou orienta e isso seria a expressão mais perfeita da unidade entre teoria e prática - na medida que ela mesmo se guia ou orienta pela própria realização de seus fins.

Nesta perspectiva, de acordo com o autor, não podemos conceber a dicotomia entre teoria e prática, mas, pelo contrário, é necessário que ocorra essa relação de interdependência entre ambas. De modo semelhante a Vázquez (2011), encontramos também na fala de Freire (2005, p. 146), concepção similar quando afirma: "[...] estamos defendendo a práxis, a teoria do fazer, não estamos propondo nenhuma dicotomia de que resultasse que este fazer se dividisse em uma etapa de reflexão e outra, distante, de ação".

Como descrito por Paulo Freire, podemos perceber também que a relação entre teoria e prática assume um caráter de dependência e convergência entre si, além de se configurar como um processo histórico, que se efetiva na relação experiência-temporalidade. Nesse sentido, Freire (1996, p. 39) ensina-nos que: "é pensando criticamente a prática de hoje ou de ontem que se pode melhorar a próxima prática". Em outras palavras, a práxis é uma construção feita diariamente, no cotidiano da ação pedagógica, portanto, um processo crítico-reflexivo e histórico.

Em resumo, de acordo com as contribuições de Vázquez (2011) e Freire (1996), uma vez que existem outras perspectivas, a práxis educativa ou pedagógica, em específico, pode ser sintetizada nas palavras de Souza (2009, p. 29) como:

[...] interrelação de práticas de sujeitos sociais formadores que objetivam a formação de sujeitos sociais que desejam ser educados (sujeitos em formação) respondendo aos requerimentos de uma determinada sociedade em um momento determinado de sua história, produzindo conhecimentos que ajudem a compreender e atuar nessa mesma sociedade e na realização humana dos seus sujeitos. 
Sob esta visão, outro aspecto a considerar, que podemos depreender do pensamento de Souza (2009) é que a práxis pedagógica configura-se como um empreendimento coletivo, participativo, no qual os sujeitos dividem um projeto político-educativo comum, ou seja, a emancipação humana. Em contraponto, na educação bancária, que se baseia numa relação que reproduz o caráter político dominante, a relação didática quase sempre ocorre na direção do professor para o aluno.

Por sua vez, a práxis pedagógica freireana, baseada na dodiscência termo que expressa a possibilidade de ensino e aprendizagem mútua entre professores e alunos -, efetiva-se na relação entre práticas docentes e discentes. Em adição, Souza (2009) ainda reconhece as práticas gestoras e epistemológicas como integrantes da práxis pedagógica ou educativa.

Portanto, partindo do pressuposto de que a práxis pedagógica ou educativa é atividade teleológica, resta-nos questionar: qual sua finalidade? De que forma ela acontece? Nesse sentido, podemos adiantar que a práxis pedagógica objetiva proporcionar aos sujeitos do conhecimento um processo emancipatório humanizante, por meio da educação, que é viabilizada pela própria prática, enquanto atividade subjetiva, objetiva e instrumentalizadora ao mesmo tempo.

Logo, respondendo às questões levantadas, Freire (2005, p. 77) ensinanos que "[...] a libertação autêntica, que é a humanização em processo, não é uma coisa que se deposita nos homens. [...] É práxis, que implica na ação e na reflexão dos homens sobre o mundo para transformá-lo". Por fim, fica claro que a práxis pedagógica freireana constrói-se paulatinamente nos processos cotidianos, formativos e laborais dos educadores e educandos, em que os próprios sujeitos são agentes realizadores de sua emancipação social, à medida que vivenciam ação e reflexão, como processo que os conduzem à transformação de sua realidade social.

\section{METODOLOGIA}

Esta pesquisa vinculou-se à abordagem qualitativa de pesquisa pela possibilidade de serem adotados métodos de acordo com a complexidade 
do objeto de estudo (FLICK, 2009). Nesse sentido, o caminho escolhido foi a análise de conteúdo para realizar a descrição e análise de uma comunicação, nesse caso, um texto (BARDIN, 2009).

Em consequência, encontramos em Bardin (2009, p. 33) a definição do método como "um conjunto de técnicas de análise de comunicações [...] marcado por uma grande disparidade de formas e adaptável a um campo de aplicações muito vasto: as comunicações". Desse modo, esta grande disparidade de formas das técnicas de análise, permite trabalhar as comunicações em diversos suportes como imagens e diferentes gêneros textuais, como livros, entrevistas e discursos, além de permitir a análise dos dados de forma qualitativa ou quantitativa. Dentro desta perspectiva, entre várias modalidades de análise de conteúdo, utilizamos a análise lexical, para a análise de um livro, que nas palavras de Minayo (2013, p. 309):

[...] inicia-se sempre pela contagem das palavras, avançando sistematicamente na direção da identificação e dimensão do texto em estudo. [...] Operacionalmente, a análise léxica se faz da seguinte forma. O pesquisador faz 0 tratamento do conteúdo de um texto mediante a identificação do número total de ocorrências de cada palavra, do número total de palavras, do número de diferentes palavras, vendo a riqueza de vocabulário utilizada para produzir uma resposta ou um discurso. A seguir ela classifica as palavras, de acordo com sua ordem na produção de significados: verbos, substantivos e adjetivos e, a seguir os vocábulos instrumentais como artigos e preposições. A partir de então, o analista reduz o número de vocábulos significativos, fazendo uma análise controlada, eliminando os artigos, preposições e as palavras que julga sem importância para o objetivo a que se propõe.

No intuito de fazer uma análise da obra Pedagogia da Autonomia, de Paulo Freire, utilizamos 0 programa de análise qualitativa Nvivo ${ }^{\circledR}$ (QSR International, 2015), versão número 11. O programa em tela proporciona várias modalidades de análise, entre as quais, elegemos a análise de frequência de palavras, que executa em poucos minutos os procedimentos descritos por Minayo (2013) relativos à análise lexical.

Em adição, o uso do programa corrobora com Bardin (2009, p. 173) na direção que "o uso do computador tem consequências sobre a prática da 
análise de conteúdo", já que entre outros motivos, a rapidez do processo aumenta e a criatividade e a reflexão são privilegiadas, em função de que o pesquisador fica livre de realizar procedimentos extenuantes.

Sendo assim, descreveremos a seguir as ações que realizamos por meio do Nvivo ${ }^{\circledR}$ no mês de junho de 2019 para chegarmos aos resultados encontrados. De início, acessamos o menu consulta e a opção frequência de palavras. Em seguida, foi aberta uma tela, na qual poderíamos selecionar alguns parâmetros antes que a ferramenta executasse sua funcionalidade. A propósito, optamos por limitar a pesquisa pelas 250 palavras mais frequentes, cujo cumprimento fosse, de no mínimo, 5 caracteres, evitando assim, o aparecimento de algumas classes de palavras pouco significativas, como por exemplo, artigos, preposições, pronomes, advérbios, conjunções, dentre outras. Sobre esta visão, Bardin (2009) denomina este conjunto como palavras-instrumento, já que desempenham uma função de ligação. Por sua vez, classes de palavras como substantivos, adjetivos e verbos são denominadas plenas, por indicarem sentido.

Em continuidade, na opção de agrupamento de palavras, optamos pela correspondência de palavras derivadas. Em consequência, a ferramenta agrupou palavras no singular e no plural, já que as mesmas separadas apenas evidenciariam o sentido de quantidade. Após a seleção dos parâmetros, procedemos à consulta e obtivemos o resultado, organizado num quadro, gerado pelo programa. Por fim, fizemos a exclusão de palavras pouco significativas que ainda apareceram, adicionando-as à lista de palavras impedidas, ou seja, aquelas que não desejávamos que constassem no resultado final.

\section{RESULTADOS E DISCUSSÃO}

Como resultado da obra analisada pela ferramenta frequência de palavras, após realizados os procedimentos descritos na metodologia, obtivemos uma tabela com 200 palavras. Por sua vez, o passo seguinte foi recortar as 07 (sete) palavras mais frequentes, listadas no quadro 1: 
Quadro 1: Sete palavras mais frequentes - Pedagogia da Autonomia

\begin{tabular}{|c|c|c|c|}
\hline Palavra & Extensão & Contagem & Palavras similares \\
\hline prática & 7 & 160 & prática, práticas \\
\hline saberes & 7 & 147 & saber, saberes \\
\hline professor & 9 & 147 & professor, professores \\
\hline mundo & 5 & 145 & mundo \\
\hline educando & 8 & 126 & educando, educandos \\
\hline ensinar & 7 & 113 & ensinar \\
\hline outro & 5 & 111 & outro, outros \\
\hline
\end{tabular}

Fonte: Adaptado de Nvivo ${ }^{\circledR} 11$ (QSR International, 2015).

Neste quadro, estão representadas nas colunas, da esquerda para direita, as palavras mais frequentes em ordem decrescente, as suas respectivas extensões em caracteres, a contagem do número de ocorrências em que aparecem no texto e, por fim, as palavras similares, agrupadas em singular e plural. Por fim, após a apresentação dos resultados, discutiremos, de forma relacional, a significância dessas palavras na obra Pedagogia da Autonomia, de Paulo Freire, conforme sua correspondência com as duas unidades temáticas criadas pelos autores, a saber: sujeitos e conhecimentos e práticas.

Como referenda Bardin (2009), a criação das categorias é um processo de classificação por diferenciação e reagrupamento, que obedece a um critério à escolha do pesquisador. No nosso caso, o critério semântico (significado, sentido) foi o escolhido para a criação das categorias e vinculação a unidade temática correspondente, como apresentado no quadro 2:

Quadro 2: Unidades temáticas e categorias - Pedagogia da Autonomia

\begin{tabular}{|c|c|}
\hline Unidades temáticas & Categorias \\
\hline Sujeitos & Professor, educandos, outro \\
\hline Conhecimentos e práticas & Saberes, ensinar, prática, mundo \\
\hline
\end{tabular}

Fonte: Elaborado pelos autores.

Por fim, com base no quadro 2 e compreendendo os limites de um artigo desse porte, vislumbramos construir uma escrita que se harmoniza tanto com a riqueza trazida pela obra freireana Pedagogia da Autonomia, 
como também trabalhar de forma sistemática com alguns trechos do livro que acreditamos atender bem ao propósito de nossa análise.

\section{Os sujeitos para Paulo Freire: protagonismo, dialogicidade e alteridade}

No que tange ao termo professor trazido por Freire na obra em apreço, a princípio questionamos: que tipo de professor seria esse sob o ponto de vista da obra Pedagogia da Autonomia? Com a finalidade de responder à esta pergunta, valemo-nos da leitura atenta de seu livro, bem como da realização de um fichamento para sintetizar as principais ideias do autor, o que nos levou a refletir de forma sistemática sobre as categorias, em um processo que envolve justamente o que Freire concebe como açãoreflexão-ação refletida. A palavra professor possui uma carga semântica que trata da representação de um ideal, que ele traz como esperança, visto que repousa na crença de um indivíduo simples e solidário. Um ser em constante ressignificação de sua práxis.

Nessa linha de raciocínio, Freire percebe o professor como uma pessoa capaz de irradiar persistência e energia para concretizar mudanças. Um profissional que não se divorcie dos aspectos que fazem parte de sua vida e que o constituem, de modo que perceba a si e o outro também, edificando um ensino que tenha como base o diálogo. O professor deve ser alguém que se debruce na superação da prática pedagógica que conceba 0 conteúdo como eixo principal que estrutura o ensino - que Freire nomeia Educação bancária -, trazendo uma abordagem revolucionária que perceba a essencialidade dos sujeitos neste processo pedagógico concretizado no chão da sala de aula, bem como da relação que se estabelece entre eles. Nessa linha, Freire (1996, p. 37) sintetiza: "Pensar certo não é que fazer de quem se isola, de quem se 'aconchega' a si mesmo na solidão, mas um ato comunicante. Não há por isso mesmo pensar sem entendimento [...]". E acrescenta:

A tarefa coerente do educador que pensa certo é, exercendo como ser humano a irrecusável prática de inteligir, desafiar o educando com quem se comunica, a quem comunica, a produzir sua compreensão do que vem sendo comunicado. 
Não há inteligibilidade que não seja comunicação e intercomunicação e que não se funde na dialogicidade (FREIRE, 1996, p. 38).

A partir desse entendimento, compreendemos o professor como sujeito mobilizador de um ensino-aprendizagem alicerçado no diálogo entre os seres que fazem parte da realidade educacional, colocando o senso crítico como eixo fundante de uma Pedagogia de cunho formativo, que instiga 0 pensar. Os educandos, nesta circunstância, são contemplados por um entendimento do aprender que os situa como protagonistas; indivíduos capazes de perceber a realidade para a conscientização.

Os educandos, homens e mulheres, constituem a base do pensamento freireano para a formulação de sua concepção sobre a realidade. O que o incomodava de modo contundente era justamente a questão das desigualdades sociais e a visão que ele considerava injusta de alguns indivíduos por conta da organização social brasileira que historicamente colocou os mais pobres à margem da sociedade, sem criar possibilidades para a sua ascensão (FREIRE, 1996). A obra Pedagogia da Autonomia lida com esse aspecto fundamental que se apóia no desvelamento da realidade e dos aspectos inerentes ao seu entendimento enquanto âmbito norteador do espírito que rege a conduta dos indivíduos em um determinado tempo e espaço.

Os sujeitos (por ele chamados também de oprimidos) despertaram em Freire uma inquietação que se tornou o norte de sua trajetória - motivo principal para a formulação de sua teoria -, mobilizando-o a idealizar mudanças para o que percebia como lacunas no sistema social e que teria na educação a oportunidade para a superação democrática dos fatores que obstaculizam o progresso de todos os sujeitos por igual. A escola tinha, segundo Freire (1996, p. 44), uma "[...] compreensão estreita do que é educação e do que é aprender". Assim nosso teórico destaca:

É uma pena que o caráter socializante da escola, o que há de informal na experiência que se vive nela, de formação ou deformação, seja negligenciado. Fala-se quase 
exclusivamente do ensino dos conteúdos, ensino lamentavelmente quase sempre entendido como transferência do saber (FREIRE, 1996, p. 43).

Como ambiente destinado ao desenvolvimento dos sujeitos, Freire questionou a escola que observou - a pública principalmente, foco de sua atenção, por lidar com o público oprimido, colocando a empatia em perspectiva para que os indivíduos percebam o outro - alguém além de si com quem necessita estar em constante comunhão de ideias para a partilha de sua visão de mundo. Motivo pelo qual Freire preocupou-se sobremaneira com a formação dos indivíduos. O trecho, destacado anteriormente, explica também que as ações desenvolvidas pelos seres que fazem parte da instituição escolar pautam-se nos moldes do sistema capitalista - expressado, sobretudo, pelo contexto do neoliberalismo - que não garante aos oprimidos a tomada de consciência para o germinar do desejo pela aprendizagem e o florescer da curiosidade.

Destarte, o olhar freireano na referida obra contempla justamente uma educação que se faz para os sujeitos com os sujeitos. Partindo de um movimento de combate às posturas que legitimam a hierarquia das relações e a concepção bancária que subordina o ensino a um instrumento que não conduz à ruptura do status quo, sem dar primazia à reflexão crítica inerente ao movimento de busca pelo conhecimento. Um movimento leal aos preceitos de uma educação que oportunize a coerência de ações desenvolvidas com empatia e respeito às peculiaridades do outro (FREIRE, 1996).

Assim, Freire (1996, p. 42) analisa que "[...] a aprendizagem da assunção do sujeito é incompatível com o treinamento pragmático ou com o elitismo autoritário dos que se pensam donos da verdade e do saber articulado". Os sujeitos da seara pedagógica, nessa visão, possuem a capacidade de reunir os atributos para adquirirem a percepção de si como seres em potencial, autores de sua própria história, conscientes de sua importância para a transformação do mundo. Protagonistas. 
Por outro lado, o livro Pedagogia da Autonomia anuncia que para a consolidação de um ambiente frutífero de aprendizagens significativas, com o intercâmbio de saberes, há de existir condições favoráveis ao fortalecimento da atividade docente. E aqui entra a questão dos esforços para o reconhecimento do papel do professor. "[...] Às vezes, as condições são de tal maneira perversas que nem se move [...]" (FREIRE, 1996, p. 66). Valorizar a docência, na ótica freireana, é valorizar, sobretudo, o espaço desses profissionais, reconhecendo a essencialidade do ensino e combatendo o esvaziamento do trabalho docente.

Nesta vertente, os sujeitos, uma vez imbuídos desse conhecimento que se pauta pelo reconhecimento de suas especificidades, trazendo seu potencial como seres críticos, devem levar em consideração a perspectiva das limitações dos saberes, que de acordo com o viés dialético, estão em permanente construção. Não cabendo aqui uma concepção de ensino sem o propósito de mergulhar na essência da educação, que caracteriza-se como ação especificamente humana (FREIRE, 1996). Em consequência, assumindo-se como lócus liberto de dogmas que reservam à ampla população o papel reprodutivista, decretando o imobilismo que de modo veemente descarta qualquer chance de ascensão social que favoreça a comunicação entre os sujeitos e sua humanização por meio da incessante busca por práticas educativas apoiadas na afetividade.

Os vocábulos professor, educandos e outro relacionam-se à categoria de sujeitos e compreendem uma visão holística da educação, ou seja, percebendo a seara educacional em sua totalidade, com a finalidade de promover reflexões sobre a razão de ser do que é ensinado, não como um repasse de conteúdos sem qualquer relação com o campo fecundo que resulta do diálogo. O cuidado, a fraternidade nas palavras e ações, a atenção, a simplicidade, o prazer em ajudar são algumas das tintas da paisagem pintada pela narrativa freireana, em sua longeva trajetória de dedicação à coletividade dos seus pares.

Finalmente, Paulo Freire (1996, p. 54) traz-nos o seguinte ensinamento: "[...] minha presença no mundo não é a de quem a ele se adapta, mas a de 
quem nele se insere. É a posição de quem luta para não ser apenas objeto, mas sujeito também da história". De quem percebe a vida como uma luta contínua pelo reconhecimento da necessidade do espírito de coletividade, consolidado por vozes e atitudes que se articulem para o abrir de olhos sobre o significado genuíno de nossa existência: ter como filosofia de vida esperançar e levantar a bandeira de uma sociedade que se sustente na emancipação dos sujeitos. Em consequência, concebendo como fundamental o livre expressar dos oprimidos, ousando estimular sua autonomia.

\section{Saberes, prática e práxis pedagógica em Paulo Freire}

No que diz respeito à palavra saberes, primeiro analisaremos o significado presente no subtítulo da obra analisada, Pedagogia da Autonomia: saberes necessários à prática educativa. Para nos auxiliar a entender o significado do termo, lançamos duas perguntas: que saberes? para que prática educativa? Para achar a resposta à primeira pergunta, necessitamos apenas ler o livro e compreender que o termo saberes, empregado por Freire é multirepresentativo e engloba não só os conhecimentos adquiridos no contexto da educação formal do educador, mas também competências, atitudes, valores políticos e ideológicos, construídos na prática social dos sujeitos.

De certa forma, o significado conferido ao termo por Freire aproximase da perspectiva de Altet apud Beillerot (2001, p. 28), ao afirmar que o "saber é aquilo que, para um determinado sujeito, é adquirido, construído, elaborado através do estudo ou da experiência". Em adição, ressalvamos que a elaboração dos saberes abordados por Freire, não se restringe somente ao âmbito das experiências profissionais dos sujeitos, mas também a suas experiências pessoais.

O modelo de professor que Freire defende, não separa sua vertente profissional, com a predominância de conhecimentos disciplinares e pedagógicos, da sua vertente pessoal, com saberes, práticas, atitudes e valores éticos, políticos elaborados na sua prática social. Na verdade, 
nenhum professor consegue separar essas duas vertentes, apenas alguns, via de regra conservadores, ainda que não se percebam assim, alegam ensinar apenas os conteúdos necessários à sua disciplina, ou seja, a tão alegada neutralidade política.

Com isso, sob a alegação de uma pretensa neutralidade política, acabam reforçando a ideologia dominante e dificultando o exercício crítico dos educandos na reflexão dos condicionantes políticos da sociedade. $\mathrm{Na}$ visão de Freire (1996, p. 71) o papel do educador progressista [...] "é o de quem testemunha o direito de comparar, de escolher, de romper, de decidir e estimular a assunção deste direito por parte dos educandos". Em suma, para Freire (1996, p. 125) "ensinar exige reconhecer que a educação é ideológica".

Em relação à segunda pergunta, podemos ter a resposta pelo excerto: "[...] meu interesse central considerar neste texto saberes que me parecem indispensáveis à prática docente de educadoras ou educadores críticos, [...] alguns deles são igualmente necessários a educadores conservadores" (FREIRE, 1996, p. 21).

Através desse excerto, percebemos que Paulo Freire centra a discussão nos saberes necessários à prática docente de educadores progressistas, ainda que alguns poucos saberes também sejam compartilhados por educadores conservadores. Partindo desse pressuposto, o autor destaca os saberes relacionados aos conteúdos da disciplina de formação do educador como essenciais à educadores críticos e conservadores na medida em que afirma: "não posso ser professor sem me achar capacitado para ensinar certo e bem os conteúdos de minha disciplina não posso, por outro lado, reduzir minha prática docente ao puro ensino daqueles conteúdos" (FREIRE, 1996, p. 103).

Por outro lado, no mesmo excerto defende que os educadores progressistas não podem reduzir sua prática docente somente ao ensino dos conteúdos da sua disciplina, sob pena de contribuírem com um processo de ensino-aprendizagem alijado de transformação social. E é aqui que reside a riqueza e importância do livro em questão na medida que Paulo Freire 
apresenta saberes de cunho epistemológico, dialógico, afetivo, da alteridade, entre outros, que incentivam o educador progressista a desenvolver a práxis pedagógica e não somente uma prática docente empobrecida de valores humanitários.

Em face da diversidade de saberes discutidos no livro, vamos destacar os de natureza afetiva e da alteridade, como representativos de uma práxis pedagógica humanizante, em contraponto às práticas atreladas à educação bancária. Sendo assim, no âmbito dos saberes afetivos, Paulo Freire diz que "ensinar exige querer bem aos educandos" (FREIRE, 1996, p. 141) no qual destacamos dois aspectos nessa discussão: Freire atesta como "falsa a separação radical entre seriedade docente e afetividade" (Ibidem, p. 141) e que "a afetividade não se acha excluída da cognoscibilidade" (Ibidem, p. 141).

Logo, para Freire a afetividade faz parte do processo de ensinoaprendizagem, contribuindo para a promoção do respeito, amorosidade e incentivo à aprendizagem entre educador e educandos. De igual modo, a seriedade do docente e sua mediação didática não são comprometidas pela afetividade, pois a prática docente de um educador progressista é pautada na ética e estética.

No que tange aos saberes da alteridade tão caros para a Pedagogia Freireana, ou seja, aqueles que dizem respeito a compreensão do outro e construção de conhecimentos com os outros, destacamos o saber escutar. Para Freire (1996, p. 119-120) este saber:

[...] significa a disponibilidade permanente por parte do sujeito que escuta para a abertura à fala do outro, ao gesto do outro, às diferenças do outro. Isto não quer dizer, evidentemente, que escutar exija de quem realmente escuta sua redução ao outro que fala. Isto não seria escuta, mas auto-anulação. A verdadeira escuta não diminui em mim, em nada, a capacidade de exercer o direito de discordar, de me opor, de me posicionar. Pelo contrário, é escutando bem que me preparo para melhor me colocar ou melhor me situar do ponto de vista das ideias. 
Em suma, podemos identificar na Pedagogia Freireana a valorização do diálogo, da escuta, do carinho entre educador e educandos, sem contudo, comprometer a seriedade e a rigorosidade científica e metodológica do processo de ensino-aprendizagem. Por outro lado, a ideologia dominante capitalista, muitas vezes difunde valores na educação como a competitividade e a meritocracia, contribuindo para a formação de cidadãos pautados na individualidade e indiferença em detrimento da coletividade e da solidariedade.

No que diz respeito à palavra ensinar, segundo este livro, está diretamente ligada ao termo saberes. Dessa forma, logo nos elementos prétextuais, mais especificamente no índice, Paulo Freire explicita a relação de exigência entre o ato de ensinar e determinados saberes, quando constrói a sentença "ensinar exige..." para nomear os tópicos dos 3 capítulos do seu livro. Consoante Freire (1996), é rechaçada a concepção de que para ser professor é necessário ter o dom de ensinar, ou dominar para além do conteúdo específico, algumas habilidades comunicacionais para o ensino. Por outro lado, fica mais evidente que para ser professor é necessário a construção de saberes específicos da docência, que são aprimorados por meio do estudo e da experiência, ratificando a exigência da profissionalização docente.

Em toda a obra aborda, basicamente, dois tipos de educação, a bancária e a problematizadora. Em consequência, cada uma delas apresenta uma concepção de ensino. Nesse sentido, Freire (1996, p. 22) logo no início do livro, destaca "[...] que ensinar não é transferir conhecimento, mas criar as possibilidades para a sua produção ou a sua construção".

Para Freire, conhecimento é construído ou produzido, em etapas, e diga-se de passagem, é um empreendimento coletivo, no qual educador e educandos "apesar das diferenças que os conotam, não se reduzem à condição de objeto, um do outro" (FREIRE, 1996, p. 23). Em adição, para Freire (Ibidem, p. 23) o ensinar está relacionado a dodiscência, postura docente que considera que: "Quem ensina aprende ao ensinar e quem aprende ensina ao aprender. Quem ensina, ensina alguma coisa a alguém". 
Apesar de o conceito de dodiscência ter sido relacionado ao educador, no qual Freire o utilizou para enfatizar a postura de aprendiz do professor, podemos também validá-lo para os educandos, que além de aprenderem com o professor podem ensiná-lo. Nesse caminho, os educandos podem compartilhar, por exemplo, conhecimentos de sua vivência, exercendo atividades ou como parentes de pescadores, pedreiros, agricultores, entre outros. Por sua vez, estes saberes da tradição popular, trazidos pelos educandos para os contextos de ensino-aprendizagem, podem não ser conhecidos pelos educadores, configurando-se assim em oportunidades de aprendizagens que dialogam com o conhecimento formal. De modo semelhante, existe uma infinidade de situações passíveis de proporcionar aprendizado aos educadores, pois os educandos como sujeitos sociais, são produtores de conhecimento.

Em suma, destacamos que para Freire, ensinar é um processo de mediação entre o conhecimento e os sujeitos que ensinam e aprendem mutuamente. Em consequência, devido à própria essência do conhecimento e do ato de ensinar, Freire (Ibidem, p. 23) explica que "Por isso é que, do ponto de vista gramatical, o verbo ensinar é um verbo transitivorelativo. Verbo que pede um objeto direto - alguma coisa - e um objeto indireto - a alguém".

No que se relaciona ao termo prática, encontramos, do ponto de vista epistemológico, um dos temas centrais da Pedagogia Freireana que é a relação entre teoria e prática, basilar para a efetivação da práxis pedagógica. Entretanto, nossa intenção é destacar, do ponto de vista comunicacional/comportamental, outro tema vinculado ao termo prática, igualmente importante, que diz respeito à coerência do educador. Em outras palavras, a coerência, que remete ao seu discurso e a sua prática, já que para Freire (1996, p. 103) "tão importante quanto o ensino dos conteúdos é minha coerência na classe. A coerência entre o que digo, 0 que escrevo e o que faço".

Decerto, através da leitura do livro, notamos que a exigência deste valor é eventualmente discutida por Freire como necessária à prática 
docente, já que suas várias dimensões devem estar bem conectadas, harmonizadas umas com as outras. Nesse sentido, o ensino dos conteúdos, o processo de aprendizagem e a avaliação como parte deste último, não podem estar em desarmonia com as dimensões ética e política da prática docente.

Em outros termos, quando o professor assume-se politicamente como progressista não deve ensinar os conteúdos, de forma predominantemente tradicional, procurando transmitir tão somente informações. Ao contrário, de forma coerente, a sua opção pelo projeto-educativo progressista deve favorecer a construção do conhecimento, problematizando e dialogando com os educandos os conteúdos. Em adição, segundo o pensamento de Freire (1996, p. 109) é premente "[...] criarmos, em nossa prática docente, entre outras, a virtude da coerência. Não há nada talvez que desgaste mais um professor que se diz progressista do que sua prática racista, por exemplo".

Por fim, Edina de Oliveira que prefaciou o livro analisado, atenta para "[...] aquilo que os estudos das ciências da educação vêm apontando nos últimos anos: a ampliação e a diversificação das fontes legítimas de saberes e a necessária coerência entre o 'saber-fazer é o saber-ser-pedagógicos'" (FREIRE, 1996, p. 10-11). Logo, depreendemos que o saber-fazer, ou seja, os conhecimentos e competências diversas necessários ao exercício da profissão docente, devem estar em estrita conexão com a projeção e efetiva vivência desses saberes na prática docente cotidiana dos educadores.

Tal reflexão provocada por Freire coloca-se como essencial, no sentido de saber ser professor, pois historicamente, observamos a dicotomia entre os discursos e as práticas das instituições e os sujeitos da educação, tanto no que se refere ao ensino básico quanto ao superior. Em suma, o que está escrito nos projetos políticos institucionais e planejamentos de ensino, muitas vezes não tem coerência com a prática docente e gestora.

Com relação à palavra mundo, fizemos três destaques, cujas ideias de Paulo Freire são direcionadas à denúncia das desigualdades sociais, à leitura 
e à intervenção no mundo. Sobre as desigualdades sociais, Freire por ter desenvolvido sua proposta de alfabetização de adultos, geralmente trabalhadores urbanos e rurais, conhecia a origem dessas pessoas. Nas suas obras, comumente encontramos referências a elas, bem como a necessidade de superação das desigualdades sociais. Como exemplo, Freire (1996, p. 130) discorre sobre a problemática do desemprego e sua relação com a ordem social, econômica e política vigente no mundo, para o qual:

O desemprego no mundo não é, como disse e tenho repetido, uma fatalidade. É antes o resultado de uma globalização da economia e de avanços tecnológicos a que vem faltando o dever ser de uma ética realmente a serviço do ser humano e não do lucro e da gulodice irrefreada das minorias que comandam o mundo.

Como forma de superação das desigualdades sociais, a Pedagogia Freireana tem como ponto de partida o processo de leitura do mundo e como ponto de culminância, a intervenção no mundo. Para tanto, Freire ao considerar que a educação como prática social pode proporcionar mudanças na vida das pessoas e que são elas os agentes dessas mudanças (1996, p. 77) parte do pressuposto de que "ninguém pode estar no mundo, com o mundo e com os outros de forma neutra. Não posso estar no mundo de luvas nas mãos constatando apenas". Sendo assim, o primeiro passo no sentido da transformação social é a compreensão da leitura de mundo do educando, pelo professor. No dizer de Freire $(1996$, p. 122) o reconhecimento e respeito à leitura de mundo do educando é fundamental, pois:

A resistência do professor, por exemplo, em respeitar a "leitura de mundo" com que o educando chega à escola, obviamente condicionada por sua cultura de classe e revelada em sua linguagem, também de classe, se constitui em um obstáculo à sua experiência de conhecimento.

Para Freire, o processo de ensino-aprendizagem é vivenciado como construção, ou mais especificamente como reconstrução do conhecimento, já que para isso é necessário partir da base de conhecimentos do educando no sentido de processar uma nova construção. Dito isto, se um educador 
não considera a leitura de mundo que o aluno chega à escola, não confrontando-a com os conteúdos sistematizados, o processo de ensinoaprendizagem tem a tendência a ser menos significativa. Tal fato é explicado, porque o educando não tem a oportunidade de confrontar os seus conhecimentos com a nova perspectiva que está sendo apresentada a ele, fazendo com que o educando tenha maior dificuldade para compreender e aprender.

Em continuidade, após o reconhecimento da leitura de mundo do educando e sua utilização como ponto de partida para a reconstrução do conhecimento, o educador progressista, deve problematizá-la, apontando algumas limitações dessa visão para explicar os fenômenos sociais e naturais. Em seguida, o conhecimento científico deve ser apresentado como elemento epistemológico que pode auxiliar o educando a ter uma visão mais complexa e crítica do mundo social e natural. Nas palavras de Freire (1996, p. 122-123) o processo descrito "É a maneira correta que tem o educador de, com o educando e não sobre ele, tentar a superação de uma maneira mais ingênua por outra mais crítica de inteligir o mundo".

Posteriormente, após o processo de construção do conhecimento de forma problematizada, dialogada e crítica, o educando estará mais apto a não só ter uma leitura de mundo mais crítica como também a intervir na transformação de sua própria realidade. Nessa direção, a possibilidade de intervenção na realidade efetiva-se a partir da passagem de uma leitura de mundo mais ingênua para uma mais crítica, por meio do processo de reconstrução de conhecimentos do senso comum para a que se baseia nos conhecimentos científicos.

Por sua vez, os conhecimentos científicos, por melhor explicarem os fenômenos sociais e naturais proporcionam ao educando o exercício de sua cidadania, tanto cumprindo os seus deveres quanto exigindo o cumprimento de seus direitos sociais. Nesse sentido, por meio do conhecimento construído e consequente apresentação de melhores argumentos sobre os mais variados temas, o educando pode participar do debate sobre as decisões que impactam a sua vida. 
Por outro lado, na visão de Freire (1996, p. 109), a educação como forma de intervenção na realidade, pode proporcionar mudanças tanto emancipatórias quanto mantenedoras do status quo, a depender da atuação ou omissão dos sujeitos sociais, pois para o autor:

Quando falo em educação como intervenção me refiro tanto à que aspira a mudanças radicais na sociedade, no campo da economia, das relações humanas, da propriedade, do direito ao trabalho, à terra, à educação, à saúde, quanto à que, pelo contrário, reacionariamente pretende imobilizar a História e manter a ordem injusta.

Outro aspecto, relacionado a esta perspectiva, da educação como forma de intervenção na realidade, diz respeito ao alcance das mudanças sociais por meio da educação. Nesse sentido, Freire (1996, p. 112) adverte que: "O educador e a educadora críticos não podem pensar que, a partir do curso que coordenam ou do seminário que lideram, podem transformar o país. Mas podem demonstrar que é possível mudar".

Portanto, para o educador progressista é indispensável a consciência de que a mudança na realidade social, realiza-se em conjunto com outros sujeitos, imbuídos do mesmo projeto político-educacional. Afinal, na vivência da práxis pedagógica, enquanto atividade conjunta de professores, alunos, gestores e demais sujeitos da educação é que a mudança na realidade efetiva-se enquanto emancipação ou permanência.

Por fim, com o intuito de proceder a uma análise relacional, compreendemos que as palavras incluídas na categoria temática em tela constituem-se como elementos e processos relacionados à práxis pedagógica, por sua vez, atividade transformadora da realidade. No que diz respeito à relação entre saberes e prática, encaminha-nos para a efetivação da práxis pedagógica, como atividade docente pautada na constante reflexão entre o saber e o fazer, ov em outras palavras entre teoria e prática. A esse respeito, encontramos em Freire (1996, p. 38) que "a prática docente crítica, implicante do pensar certo, envolve o movimento dinâmico, dialético, entre o fazer e o pensar sobre o fazer". 
Em relação, aos termos ensinar e mundo, conduzem-nos a pensar um processo de mediação entre o ensino-aprendizagem e a intervenção no mundo, traduzida na perspectiva de uma práxis pedagógica, construída coletivamente e historicamente, pela soma das diversas práxis. Por certo, as práxis docente e discente requerem a adesão a um projeto político educacional, congruente com a libertação da opressão. Na visão de Freire (1996, p. 69-70):

[...] toda prática educativa demanda a existência de sujeitos, um que, ensinando, aprende, outro que, aprendendo, ensina, daí o seu cunho gnosiológico; a existência de objetos, conteúdos a serem ensinados e aprendidos; envolve o uso de métodos, de técnicas, de materiais [...].

Em suma, o ato de ensinar na perspectiva freireana, efetiva-se por meio dos métodos, técnicas e recursos didáticos, ou seja, como forma de mediação entre o conhecimento e os sujeitos do processo de ensinoaprendizagem. Assim, o ato de ensinar, que possibilita reciprocamente o de aprender confere aos sujeitos a viabilidade de mudar a sua realidade, por meio do conhecimento dos seus direitos e deveres na sociedade, de forma a reivindicar a sua cidadania plena.

\section{CONSIDERAÇÕES FINAIS}

Respondendo ao objetivo geral - discutir conceitos da Pedagogia Freireana, a partir das sete palavras mais frequentes no livro Pedagogia da Autonomia, cuja operacionalização foi guiada pelos objetivos específicos de identificar as sete palavras mais frequentes e relacionar as mesmas palavras a unidades temáticas, para melhor análise dos vocábulos, e mais precisamente segundo a análise dos dados, podemos fazer algumas considerações.

A primeira, sem ainda entrar no mérito da análise dos dados, consiste na constatação do amplo reconhecimento da figura e da obra de Paulo Freire pelo mundo, materializado por inúmeras homenagens, títulos acadêmicos em diversas universidades do país e do exterior, traduções de 
suas obras para diversas línguas e até monumentos. Sendo assim, compartilhamos uma provocação: como as ideias de um educador com tanto reconhecimento internacional, podem ser responsáveis pelo fracasso da educação no país, como difundem os grupos sociais simpatizantes ao atual presidente brasileiro?

Em segundo, a discussão, a partir das sete palavras mais frequentes encontradas no livro Pedagogia da Autonomia aqui denominadas de categorias (de análise) permitiram-nos encontrar conceitos e ideias pedagógicas pertencentes a algumas das principais categorias da Pedagogia Freireana, a saber: dialogicidade, práxis, emancipação e humanização. Em consequência, no aprofundamento da discussão das categorias anteriormente citadas, encontramos conceitos e ideias relacionadas aos sujeitos do processo de ensino-aprendizagem e aos saberes e princípios pedagógicos da pedagogia difundida pelo autor.

Desse modo, foram discutidos aspectos ligados à racionalidade comunicativa, como dialogicidade, intersubjetividade e alteridade como conceitos necessários à mediação pedagógica entre educadores e educandos. No campo epistemológicos, saberes e práticas que conduzem a práxis pedagógica, capazes de transformar a realidade dos educandos em direção à emancipação e à humanização.

Em suma, diante do que foi discutido, reafirmamos que os princípios da Pedagogia Freireana contribuem para um modelo de ensino-aprendizagem, democrático, humanista e emancipatório. Em outras palavras, educadores e educandos têm a oportunidade de ensinar e de aprender, em um ambiente pedagógico, pautado pelo diálogo, ética e respeito aos saberes do outro, cujo fim perseguido é a emancipação e humanização dos sujeitos, em detrimento da perpetuação das desigualdades sociais.

Por fim, com base na análise dos dados, esperamos ter apresentado subsídios para responder nosso objetivo político neste estudo - demonstrar por meio de dados científicos, fundamentados na obra de Paulo Freire, a preocupação do autor em apresentar uma Pedagogia pautada em ideais de valorização do ser humano. 


\section{REFERÊNCIAS}

ALTET, M. As competências do professor profissional: entre conhecimentos, esquemas de ação e adaptação, saber analisar. In: PAQUAY, L. et al. (org.). Formando professores profissionais: quais estratégias, quais competências. Porto Alegre: Artmed, 2001.

BARDIN, L. Análise de conteúdo. Lisboa: Edições 70, 2009.

BETTO, F. Por uma educação crítica e participativa. Rio de Janeiro: Anfiteatro, 2018.

FLICK, U. Introdução à pesquisa qualitativa. Porto Alegre: Artmed, 2009.

FRANCO, M. A. R. S. Pedagogia e prática docente. São Paulo: Cortez, 2012.

FRANCO, M. A. R. S. Da necessidade/atualidade da pedagogia crítica: contributos. Revista Reflexão e Ação, v. 25, n. 2, p. 154-170, 2017.

FREIRE, P. Pedagogia da autonomia: saberes necessários à prática educativa. São Paulo: Paz e Terra, 1996.

FREIRE, P. Pedagogia do oprimido. São Paulo: Paz e Terra, 2005.

LIMA, L. C. Crítica da educação indecisa: a propósito da pedagogia da autonomia de Paulo Freire. Revista E-Curriculum, v. 7, n. 3, p. 1-12, 2011.

MELO, G. F. Pedagogia universitária: aprender a profissão, profissionalizar a docência. Curitiba: CRV, 2018.

MINAYO, M. C.S. O desafio do conhecimento: pesquisa qualitativa em saúde. São Paulo: Hucitec, 2013.

POLLI, J. R. Paulo Freire: o educador da esperança. Jundiaí: In House, 2008.

QSR International for NVIVO. Versão 11. [S.I], QSR International, 2015. Disponível em: https://www.qsrinternational.com/nvivo-qualitative-dataanalysis-software/support-services/nvivo-downloads. Acesso em: 01 de junho de 2020.

SOUZA, J. F. Prática pedagógica e formação de professores. Recife: EDUFPE, 2009.

VÁZQUEZ, A. S. Filosofia da práxis. São Paulo: Expressão Popular, 2011. 
Recebido em: 11 de setembro de 2020

Aprovado em: 19 de outubro de 2020

Publicado em: 05 de novembro de 2020

(c) $\underset{\mathrm{Br}}{(\mathbf{1})(9)}$ 